\section{Case Reports in Neurology}

Case Rep Neurol 2020;12:387-401

DOI: 10.1159/000509073

Published online: November 9, 2020

2020 The Author(s)

Published by S. Karger AG, Basel

www.karger.com/crn

This article is licensed under the Creative Commons Attribution-NonCommercial 4.0 International License (CC BY-NC) (http://www.karger.com/Services/OpenAccessLicense). Usage and distribution for commercial purposes requires written permission.

\title{
Neuropsychiatric Aspects in a Patient Diagnosed with Corticobasal Degeneration: Clinical Case of Low Incidence and Prevalence in Colombia
}

\author{
Carlos Alberto Hurtado González ${ }^{a}$ b Carolina Piedrahita ${ }^{c}$ \\ Diana Vivas Álzatec Juan José García Borrero ${ }^{d}$ \\ Carlos Steven Marmolejo Escobar ${ }^{\mathrm{e}}$ Sebastián Ospina Otalvaro ${ }^{\mathrm{e}}$ \\ Pablo Miguel Arango f, g Paola Andrea Gutiérrez Lenis ${ }^{\mathrm{h}}$ \\ Daniela Díaz Varela ${ }^{d}$ Estela López Molano ${ }^{e}$ \\ Danny Vanesa Allin Ramírez ${ }^{k} \quad$ Ausberto Rinco ${ }^{j} \quad$ Juanita Sánchez ${ }^{i}$ \\ Viviana Hernándezi Researcher Team on Basic and Applied Clinical \\ Neurosciences SEMINEC Researcher Team on Psychiatry, School of \\ Medicine, Libre University Cali Colombia CINEPSIS \\ aSchool of Psychology, Cooperativa University Cali Colombia, Cali, Colombia; ${ }^{b}$ School of \\ Medicine and Psychiatry Department, Libre University, Cali, Colombia; 'Specialty of

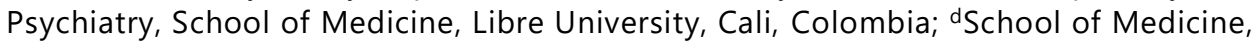 \\ Libre University, Cali, Colombia; eSchool of Psychology, Cooperativa University, \\ Cali, Colombia; ${ }^{f}$ Valle University, Cali, Colombia; ${ }^{9}$ Functional Neurosurgery, Toronto \\ University, Toronto, ON, Canada; hPsychology School, Cooperativa University, \\ Cali, Colombia; iPublic Health Group, Iberoamerican University Corporation, \\ Bogotá, Colombia; jSchool of Medicine, Libre University, Cali, Colombia; ${ }^{k}$ Catholic \\ University, Bogotá, Colombia
}




\section{Case Reports in Neurology}

Case Rep Neurol 2020;12:387-401

DOI: $10.1159 / 000509073$

(C) 2020 The Author(s). Published by S. Karger AG, Basel www.karger.com/crn

Hurtado González et al.: Corticobasal Degeneration in Colombia: A Case Report

\title{
Keywords
}

Attention - Corticobasal degeneration - Neurocognitive functioning - Executive functions .

Memory · Frontal lobe

\begin{abstract}
Corticobasal degeneration (CBD) is a pathology of low incidence and prevalence worldwide; it is accompanied by symptoms such as dystonia, rigid akinetic syndrome (bradykinesia), gait disturbances, neurological deterioration associated with severe cortical subcortical atrophy, and progressive to moderate to severe neurocognitive deficits, especially in immediate verbal memory and dorsolateral or dysexecutive syndrome. We identified neurocognitive impairment and neuropsychiatric symptoms in a patient diagnosed with CBD. Participant was a 70-yearold female patient, single; she presented progressive memory loss of an immediate verbal nature. Initially, she was diagnosed with Alzheimer's disease and Lewy body dementia, finding that she had no characteristic signs and symptoms of these pathologies. The patient presented conciliation insomnia, gait disturbances, and severe neurocognitive deficit, especially in executive functions, immediate verbal memory, and visuospatial functioning. It was found that the patient presented neurocognitive alterations of the executive type (frontal lobe) such as decision making, planning, inhibition and operative memory, correlated with a severe alteration in her basic, instrumental and advanced activities of daily life, with a high risk factor for developing dementia. It is necessary to diagnose in an assertive and timely manner in order to generate functional neurorehabilitation plans in people diagnosed with CBD, with the main objective of positively impacting quality of life, at the individual, family, and social level.
\end{abstract}

(C) 2020 The Author(s)

Published by S. Karger AG, Basel

\section{Introduction}

Corticobasal degeneration (CBD) is a pathology of low incidence and prevalence worldwide [1-3], and is characterized by symptoms such as dystonia, rigid akinetic syndrome (bradykinesia), gait problems, neurological impairment associated with severe subcortical cortical atrophy and moderate severe neurocognitive deficits of a progressive type, especially in immediate verbal memory and dorsolateral and/or dysexecutive syndrome.

CBD is a neuropsychiatric pathology that is also associated with neurobehavioral and/or emotional disorders such as depression and anxiety (Fig. 1) [4]. Depression is the most frequent neurobehavioral disorder that occurs in patients with this type of diagnosis. It has been found that $[4,5]$ depressive symptoms in CBD have an impact on the worsening of quality of life (QoL), specifically in areas of emotional well-being, activities of daily living, and social and individual aspects in each of the patients. Other studies indicate that CBD correlates with the deficit that patients present in tasks of immediate verbal memory, executive functioning (planning, conceptualization, and inhibition) [5] (Fig. 1).

Other studies indicate that anxiety overlaps with mixed clinical pictures of depression and generalized anxiety, generating in the patient with CBD worsening in QoL and a possible deficit in operative memory. 


\section{Case Reports in Neurology}

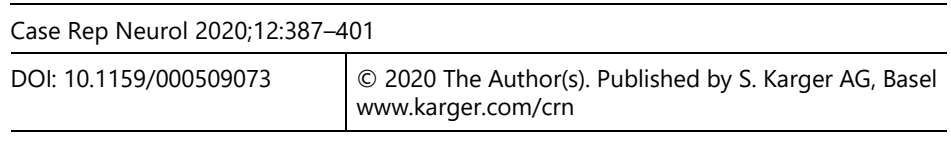

Hurtado González et al.: Corticobasal Degeneration in Colombia: A Case Report

Different investigations [6] have found that CBD is associated with a diagnosis of severe subcortical cortical atrophy, which results in a deficit and/or cerebral dysfunction in the frontal lobe, associated with a decline in executive functions, operative memory and loss of decision-making.

Currently, the scientific literature on this pathology is scarce, and thus the signs and symptoms presented by the patient may be overlapping or confused with Parkinson's or Alzheimer's disease in advanced stages.

\section{Objective}

The objective of this article is to identify the neuropsychiatric alterations presented by a patient diagnosed with CBD, a clinical case of low incidence and prevalence in Colombia.

\section{Case Report/Case Presentation}

\section{Method}

Design

The design of the report is transectional-descriptive. The case report was taken at a clear and specific time to attend the patient.

Participant

A 70-year-old patient with progressive memory loss of an immediate verbal nature. She was initially diagnosed with Alzheimer's disease and Lewy bodies dementia and was found to have no signs and symptoms of these pathologies.

The patient has difficulty in falling asleep, gait problems and severe neurocognitive disorders, especially in executive functions, temporal lobe, and visuospatial functioning.

The patient did not present any characteristic clinical signs in the production (Broca's aphasia) or language comprehension (Wernicke's aphasia), in the same way, the syndrome of other people's hands was not identified in the evaluation or in her clinical history.

\section{Physical Examination}

The patient presents phases of hyponymy, lost gaze, gait difficult, trembling in the mouth, marked bradykinesia and increased base of support.

Pharmacological Treatment

- Memantine $10 \mathrm{mg} 1$ every $12 \mathrm{~h}$.

- Rivastigmine patches $27 \mathrm{mg}$ per day.

\section{Neuroimaging Studies}

The ventricular system, prominent grooves and cisterns due to involutive changes of the cerebral parenchyma, with greater affectation of the fronto-parieto- temporal area of the brain, presents severe compromise at the hippocampal level. Clinically correlated with grade III hippocampal atrophy (Fig. 2). 


\section{Case Reports in Neurology}

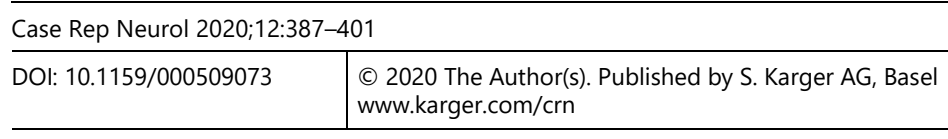

Hurtado González et al.: Corticobasal Degeneration in Colombia: A Case Report

The difference between gray and white substance is preserved, it presents multiple hyper intensities of white substance of fronto-parietal location and base nuclei.

Diagnosis of Neuroimaging Studies

1 Severe cortico-subcortical atrophy, clinically associated with involutional changes of the cerebral parenchyma with fronto-parieto-temporal involvement and severe grade III hippocampal involvement.

2 Fronto-parietal leukopathy of non-specific aspect probably microangiopathic.

\section{Materials}

Neuropsychological Evaluation (Table 1)

- Mini-Mental State Examination-MMSE: is a short cognitive screening test, it evaluates cognitive functions, it is made up of 30 sections and grouped into five dimensions: orientation (10 points), fixation ( 3 points), orientation ( 5 points), calculation and memory ( 3 points), language ( 8 points) and visuoconstructive skills (1 point) [7].

- Montreal Cognitive Assessment Scale (MOCA): This is a specific type neurocognitive test that measures executive functions, attention, immediate and deferred verbal memory, and visuospatial/visuoconstructive domains. It has $90 \%$ greater sensitivity and specificity than the MMSE [8].

- Wechsler digit range scale: This is a sub-test of the WAIS that aims to measure levels of attention and immediate verbal memory in the subject [9].

- Yesavage Geriatric Depression Scale: is a questionnaire that aims to assess depressive symptoms, consisting of 30 items. The scores are: 1-9 normal; 10-22 mild depression and 2330 severe depression [10].

- Beck Anxiety Inventory [11] This is a Likert-type scale whose objective is to evaluate the symptoms of anxiety, consisting of items that are in turn divided into subjective and somatic symptoms. It has a score of 4 points for each question (absolute, mild, moderate, severe). The sum of its items includes minimal, mild, moderate and severe anxiety.

- Trail Making Test: paper and pencil test that aims to measure levels of attention (part A). The subject must join the numbers 1-25 consecutively, and the executive functions (part B), which consists of joining the numbers 1-25, but alternating with letters (1A-2B-3C-4D-5E successively). The subject should perform the test in the shortest possible time [12].

- Babcock's history: it aims to evaluate verbal and deferred memory. The test is presented by auditory route [13].

- Clock Test: is a neurocognitive test that aims to evaluate cognitive functioning in patients with neurological or neurodegenerative diseases. It is a highly sensitive test to detect dementia due to Alzheimer's or Parkinson's disease [14].

- Frontal Assessment Battery FAB: This is a specific test that measures executive (frontal lobe) functioning or low neurocognitive performance in older people or those diagnosed with a neurodegenerative disease [15].

- Neuropsychiatric Inventory NPI: It is a test that aims to evaluate the intensity and frequency of neuropsychiatric disorders. The test is divided into the following sub-sections: delusions, hallucinations, agitation/aggression, depression, anxiety, euphoria, apathy, 


\section{Case Reports in Neurology}

Case Rep Neurol 2020;12:387-401

DOI: $10.1159 / 000509073$

(c) 2020 The Author(s). Published by S. Karger AG, Basel www.karger.com/crn

Hurtado González et al.: Corticobasal Degeneration in Colombia: A Case Report

disinhibition, irritability, aberrant motor behavior, sleep and appetite. The frequency scoring system ranges from $0-4$ and severity from 1-3, with a total score of 144 and 123 as the cutoff point for determining a neuropsychiatric profile [16].

- Verbal Fluidity: This is a test that aims to evaluate the speed of the subject's information processing. You are asked to name animals and people in one minute. It is also done in an alternate manner, the subject must name a word, alternating it with a category that the evaluator requires. Your score is obtained by the sum of each of the items.

- General Health Questionnaire GHQ-28: This is a questionnaire that evaluates self-perception of health. The test is grouped into four sections of seven items (somatic symptoms, anxiety/insomnia, social dysfunction and depression). A score greater than or equal to 23 points is a possible indicator of a psychiatric condition [17].

- Barthel's Index: This is a questionnaire that aims to assess the level of functional independence that subjects present when carrying out basic activities of daily living (BVDL) [18].

- Lawton and Brody's Scale: a questionnaire to assess the level of functional independence presented by subjects to carry out instrumental activities of daily living [19].

\section{Procedure}

The evaluation was carried out taking into account the following steps:

1 Knowledge interview with family member and patient.

2 Review of medical history and records.

3 Neuropsychological evaluation.

4 Neuropsychological report.

5 Functional plan for neurorehabilitation.

\section{Results}

\section{Emotional Picture}

The values of the scales in depression and anxiety show that the patient presents a mixed clinical picture of depression and generalized anxiety, with more prevalence of anxiety as a clinical picture of psychomotor agitation than depression as an emotional affectation. Both clinical entities are influencing the deterioration of the patient's CVD. The score of the scales shows that we are facing a neuropsychiatric profile that requires intervention from a multidisciplinary approach and immediate character.

\section{Brief Cognitive Tracking}

MMSE: The results of the test indicate that the patient is oriented in time, place, and space in a partial way. At a general level, neurocognitive alterations are identified in each of the subsections of the MMSE. The results in this test tend to point to a possible dementia, but the signs and symptoms of the patient lead to a comparative picture with a neurodegenerative disorder such as CBD. The patient's symptoms show a high neurological and/or neurocognitive deterioration that is not clinically correlated with a picture of frontotemporal, Alzheimer's, vascular dementia, or Lewy body dementia. 


\section{Case Reports in Neurology}

Case Rep Neurol 2020;12:387-401

DOI: $10.1159 / 000509073$

(c) 2020 The Author(s). Published by S. Karger AG, Basel www.karger.com/crn

Hurtado González et al.: Corticobasal Degeneration in Colombia: A Case Report

\section{Specific Cognitive Functioning}

\section{Attention}

In the specific tests of neurological and/or neurocognitive functioning, it was found that the patient presents a moderate-severe deficit in sustained attention tasks, the patient cannot retain new and immediate information, an alteration that is associated with the dysfunction she presents in her operating memory, which does not allow her to condense and store information, These data are verified in the TMT form A test. The duration that the patient had in the test makes it clinically possible to infer that her alteration in attention tasks are a predictive factor for the progression to a greater alteration in her attentional processes, specifically related to the fronto-subcortical circuits, which may be generating alterations in motor functions and specific aspects of her behavior.

The data in these tests indicate possible dysfunction in the upper and middle orbitofrontal gyrus and sulcus, brain structures associated with inhibitory behavior, learning and deficits in their working memory.

\section{Executive Functions}

In the tests that apply to this section, it was found that the patient presents severe alterations to plan, organize, direct, and control her immediate behavior. The patient is not able to manage several dimensions at the same time, which are related to neurobehavioral disorders such as depression and anxiety (especially anxiety) generating a low neurocognitive performance in tests that handle different sequences such as TMT form B. The time taken by the patient in this test leads us to infer that there is a possible alteration of a focused type in her prefrontal court, dorsolateral cortex and upper and middle orbitofrontal gyrus of her brain, brain areas that have as a main component the executive functions and the domain of the immediate behavior, especially the management of tasks that imply aspects of inhibition.

The MOCA test showed the alterations presented by the patient in recording tasks and coding the information in its operating memory. The results obtained in the MOCA lead to the inference that we are dealing with a clinical case that is not associated with dementia, but with a neurological/neurocognitive deterioration and progressive extrapyramidal involvement.

The above data are verified by the FAB test (neurocognitive test of executive functions). The patient had a score below the cut-off point, which may be associated with a clinical picture of pro-Alzheimer's dementia, but in the patient it is different, since the results only show that she does not have a clinical picture of dementia, but that the deterioration of his executive functions are a predictive factor for him to later present a clinical diagnosis of Alzheimer's disease dementia that overlaps with CBD. For this reason, it is necessary to intervene in a timely manner with a treatment plan for functional neurorehabilitation that aims to slow down his disease and improve his CVD.

In tasks of verbal fluency, the patient is unable to evoke information, alterations associated with a language problem are identified, her speech is not fluent, at times she tries to be spun, but is lost in her immediate context.

Memory

In this section, it was identified that the patient in immediate verbal memory (Babcock's history) has little ability to consolidate, store and evoke information. This is clinically 


\section{Case Reports in Neurology}

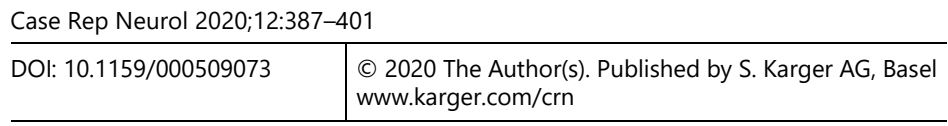
www.karger.com/crn

Hurtado González et al.: Corticobasal Degeneration in Colombia: A Case Report

associated with a possible dysfunction in the cell wall of the hippocampus and related brain structures such as fimbria and alveus. The data obtained in these scales indicate that the patient is presenting a severe neurocognitive impairment associated with age and CBD that is presenting.

Visuospatial Functioning/Visuoconstructive Skills

In this neurocognitive domain, it was identified that the patient presents severe difficulties in processing information of a mental and/or spatial nature, cannot process or manipulate information in different contexts. The results of the tests in this domain (Clock Test) demonstrate what we have inferred in the section on executive functions; the deterioration in her visuospatiality is related to the deficit she presents in executive functions, specifically in her frontal lobe, where it is necessary to intervene in a timely manner, since the tests used reveal that in the short term, the patient may enter a clinical picture of dementia due to Alzheimer's disease and/or dementia of a mixed nature.

Basic, Instrumental and Advanced Activities of Daily Life

The patient presents a moderate-severe degree of dependency; she is NOT able to perform much of the daily activities of her daily life.

\section{Differential Diagnostics}

The differential diagnosis of the patient was made with the following neurodegenerative pathologies.

Alzheimer's disease: The patient presents alterations in the immediate verbal memory, but it was identified that there is no major alteration in her executive functions as a predictor for Alzheimer's disease dementia; adequate verbal fluency was also found, and the handling of a second language that allows her to be a protective factor for this pathology.

Frontotemporal dementia: The patient presents a late age to be diagnosed with this pathology; it was found that there are no alterations as aberrant motor behavior, repetitive compulsive behavior, loss of judgment and inhibition, apathy and extreme hyper-orality.

Lewy bodies dementia: Although the patient presents neurocognitive alterations of a progressive type, correlated with cardinal motor symptoms typical of Parkinson's disease, we can infer that it is not dementia with Lewy bodies, since the patient does not experience hallucinations of a visual type, a relevant symptom in this pathology.

$C B D$ : This neurodegenerative pathology is insidious and slowly progressive. The patient is in adulthood and suffers from asymmetric/bradykinetic Parkinsonism and moderate to severe neurocognitive impairment, specifically in attention tasks, working memory and executive functions.

The patient has the following symptoms:

(a) Movement disorders: The patient presents moderate to severe bradykinetic Parkinsonism, accompanied by dystonia, postural tremor, myoclonus, and pyramidal affectation associated with possible ideomotor apraxia.

(b) Neurocognitive alterations: Specifically in attention tasks, operative memory, and executive functions. 


\section{Case Reports in Neurology}

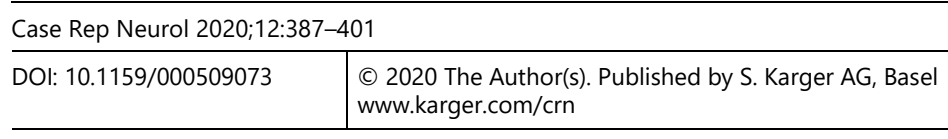

Hurtado González et al.: Corticobasal Degeneration in Colombia: A Case Report

(c) Cortical-subcortical atrophy: The patient's imaging study shows widening of cerebral grooves at the height (cortical) and internal (subcortical) of the cerebral cortex, generating volumetric reduction in the brain and affecting each of the patient's neurocognitive domains.

Health Self-Perception Questionnaire - GHQ-28

The results of this scale show that the patient presents a mixed clinical picture of depression and generalized anxiety.

Diagnostic Print

- Moderate-severe neurocognitive impairment of a progressive type.

- Neurocognitive impairment in immediate verbal memory, sustained attention and moderate-severe dysexecutive syndrome.

- Mixed clinical picture of moderate-severe depression and generalized anxiety.

- Advanced CBD.

Functionality

Because of the patient's clinical condition, we suggest:

- Treatment of functional neurorehabilitation by clinical neuropsychology, with the aim of slowing down the diagnosis of basal cortical degeneration to a clinical picture of dementia due to Alzheimer's disease.

- Generate a greater degree of independence in basic, instrumental and advanced activities of their daily life.

- Establish social and family action plans that aim to improve their QoL.

- It is necessary to immediately begin a neurorehabilitation process, with the aim of preserving and strengthening brain structures and cognitive reserve, which serve as a protective factor in the patient for possible Alzheimer's dementia.

Forecast and Plan for Functional Neurorehabilitation

It is necessary to generate a functional neurorehabilitation plan that aims at the following intervention targets:

- It is necessary that three times a week the patient receives attention and intervention by clinical neuropsychology, with the objective of establishing therapeutic intervention targets that manage to minimize the negative impact of her neurological deterioration. This work should be focused on each of the neurocognitive domains (attention, memory, executive functions, visuospatial functioning, and visuoconstructive skills).

- Psychosocial work to reinforce the activities of daily living.

- Intervention by clinical psychology, with the aim of lowering their emotional reactivity.

The functional neurorehabilitation proposal has not been implemented with the patient; it is simply a non-pharmacological line of treatment that aims to improve her QoL. 


\section{Case Reports in Neurology}

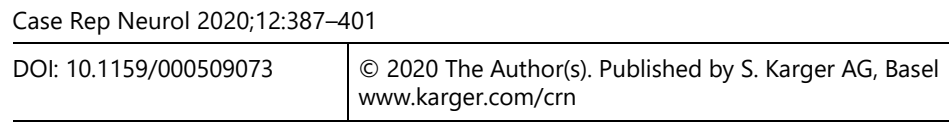
www.karger.com/crn

Hurtado González et al.: Corticobasal Degeneration in Colombia: A Case Report

\section{Discussion/Conclusion}

CBD is a neuropsychiatric condition associated with neurobehavioral disorders such as depression and anxiety, with depressive symptoms being more prevalent than clinical manifestations of psychosocial stress (anxiety) [20]. It was found that the patient presents a worsening of her CVD associated with a decline in emotional well-being, low self-esteem and a worsening of basic, instrumental and advanced activities of daily living, data which has been confirmed by other research, which indicates that the CVD of people with CBD is related to a worsening in each of their individual, social and family domains [20].

Anxiety was also found to impact on the worsening of CVD, working memory and basic, instrumental, and advanced activities of daily living [4,20].

Neurocognitive deficits $[4,21]$ are associated with immediate verbal memory loss, dorsolateral and/or dysexecutive syndrome (Fig. 3). This deficit presented by the patient is a predictor of later treatment of a clinical picture of dementia.

For this reason, it is necessary to implement new studies that aim to carry out more systematic investigations, with experimental designs and deeper study types, this will allow the lines of action to have a single purpose, to investigate and intervene.

Functional neurorehabilitation plans with a single goal are required. To improve the patient's QoL, we present (Fig. 4) the following proposal that aims to slow down the disease to more advanced stages.

1 Every patient who is treated with a neurodegenerative pathology will present neurobehavioral and/or emotional alterations such as depression and anxiety. These alterations have repercussions on the QoL and the neurocognitive functioning, for which the work of the following is necessary:

2 Psychologist, competent professional who will have as a purpose with the patient to lower the emotional reactivity.

3 Neurologist: This specialist aims to promote a healthy state of the patient, his work should be reinforced by

4 Psychiatry, since an adequate pharmacological treatment will allow to generate degrees of emotional stability in the patient.

5 Clinical neuropsychologist: his only objective is to generate greater neurocognitive plasticity, thus seeking to slow the progress of the disease to stages of dementia.

6 Immediate caretaker: the role of the immediate caretaker is of great importance, since it will allow the patient to be regulated in each of his/her individual, family and social contexts. Similarly, the mental health of the caregiver needs to be taken into consideration, as they present a high risk factor for burnout syndrome.

This proposal is aimed at alleviating motor and non-motor symptoms in patients with CBD.

Unfortunately, neurocognitive deterioration in patients with CBD is much more progressive than in patients with Alzheimer's and Parkinson's disease. However, the aim of this proposal is to slow down the degree of cortico-subcortical atrophy presented by the patient, and thus prevent her from reaching a clinical picture of dementia in advance.

We hope that this article will contribute to generate new lines of research in neurodegenerative diseases, especially in CBD, and thus, contribute to the improvement of patients' QoL. 


\section{Case Reports in Neurology}

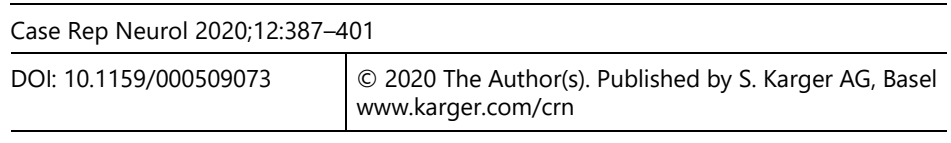

Hurtado González et al.: Corticobasal Degeneration in Colombia: A Case Report

\section{Acknowledgement}

We thank the patient and her immediate caregiver for making the investigation possible in her clinical case.

\section{Statement of Ethics}

The patient and his or her companion, in agreement with the researchers, signed an informed consent form indicating the process to be carried out with the patient. They were guaranteed the protection of their personal data. The patient was told that the evaluation was paper and pencil and that it presented no physical risk. The study was carried out taking as a reference the ethical principles for the development of research or experimentation on human beings, in this case, the Declaration of Helsinki, the Declaration of Bern and resolution 008430 of 4 October 1993 of the Ministry of Social Protection of the Republic of Colombia for the ethical aspects of research on human beings.

The authors have no ethical conflicts to disclose.

The authors state that the patient and their immediate caregiver gave their approval to write and publish the article, including their clinical history, neuroimaging tests and the results of the evaluation protocol.

\section{Conflict of Interest Statement}

The authors declare that there is no conflict of interest.

\section{Funding Sources}

The authors declare that there was no funding of any kind in this research project.

\section{Author Contributions}

Each of the authors had a role of evaluation, diagnosis and writing of the article.

\section{References}

1 Levin J, Kurz A, Arzberger T, Giese A, Höglinger GU. The Differential Diagnosis and Treatment of Atypical Parkinsonism. Dtsch Arztebl Int. 2016 Feb;113(5):61-9.

2 Wenning GK, Litvan I, Jankovic J, Granata R, Mangone CA, McKee A, et al. Natural history and survival of 14 patients with corticobasal degeneration confirmed at postmortem examination. J Neurol Neurosurg Psychiatry. 1998 Feb;64(2):184-9.

3 Stamelou M, Bhatia KP. Atypical parkinsonism: diagnosis and treatment. Neurol Clin. 2015 Feb;33(1):39-56. 


\section{Case Reports in Neurology}

\begin{tabular}{l|l}
\hline Case Rep Neurol 2020;12:387-401 \\
\hline DOI: 10.1159/000509073 & $\begin{array}{l}\text { @ 2020 The Author(s). Published by S. Karger AG, Basel } \\
\text { www.karger.com/crn }\end{array}$ \\
\hline
\end{tabular}

Hurtado González et al.: Corticobasal Degeneration in Colombia: A Case Report

4 Kertesz A, McMonagle P. Behavior and cognition in corticobasal degeneration and progressive supranuclear palsy. J Neurol Sci. 210;289(1-2):138-143. https://doi.org/10.1016/j.jns.2009.08.036

5 Baquero M, Martín N. Depressive symptoms in neurodegenerative diseases. World J Clin Cases. 2015;3(8):682. https://doi.org/10.12998/wjcc.v3.i8.682.

6 Moretti R, Torre P, Antonello RM, Cattaruzza T, Cazzato G. Cognitive impairment in the lateralized phenotype of corticobasal degeneration. Dement Geriatr Cogn Disord. 2005;20(2-3):158-62.

7 Lobo A, Saz P, Marcos G; Grupo ZARAMDEMP. Mini-Mental Status Examination. Madrid: Tea ediciones; 2001.

8 Nasreddine ZS, Phillips NA, Bédirian V, Charbonneau S, Whitehead V, Collin I, et al. The Montreal Cognitive Assessment, MoCA: a brief screening tool for mild cognitive impairment. J Am Geriatr Soc. 2005 Apr;53(4):695-9. https://doi.org/10.1111/j.1532-5415.2005.53221.x.

9 Weschsler D. Weschsler Memory Scale. New York: The Psychological Corporation; 1972.

10 Yesavage JA, Sheikh JI. 9/Geriatric depression scale (GDS) recent evidence and development of a shorter version. Clin Gerontol. 1986;5(1-2):165-73.

11 Beck A, Steer R. Manual BAI. Inventario de Ansiedad de Beck (adaptación española de J. Sanz). 2011.

12 Reitan RM. Trail Making Test: Manual for administration and scoring. Tempe: Reitan Neuropsychology Laboratory; 1992.

13 Babcock H. An experiment in the measurement of mental deterioration. Arch Psychol. 1930;117:105.

14 Cacho-Gutierrez LJ, García-García R, Arcaya-Navarro J, Lantada N. Una propuesta de aplicación del test del reloj en la enfermedad de Alzheimer. Rev Neurol. 1999;28:648-55.

15 Dubois B, Slachevsky A, Litvan I, Pillon B. The FAB: A frontal assessment battery at bedside. Neurology. 2000 Dec;55(11):1621-6.

16 Cummings JL, Victoroff JI. Noncognitive neuropsychiatric syndromes in Alzheimer's disease. Neuropsychiatry Neuropsychol Behav Neurol. 1990;3(2):140-158.

17 Lobo A, Pérez-Echeverría MJ, Artal J. Validity of the scaled version of the General Health Questionnaire (GHQ-28) in a Spanish population. Psychol Med. 1986 Feb;16(1):135-40.

18 Mahoney F, Barthel DW. FUNCTIONAL EVALUATION: THE BARTHEL INDEX. Md State Med J. 1965 Feb;14:61-5.

19 Lawton MP, Brody EM, Saperstein AR. A controlled study of respite service for caregivers of Alzheimer's patients. Gerontologist. 1989 Feb;29(1):8-16.

20 Stamelou M, Kailash B. Dementia in Parkinson's Disease and Atypical Parkinsonism. Movement Disorders in Dementias. London: Springer; 2014. pp 179-97.

21 Oliveira LM, Barcellos I, Teive HA, Munhoz RP. Cognitive dysfunction in corticobasal degeneration [Internet]. Arq Neuropsiquiatr. 2017 Aug;75(8):570-9. [cited 2020 May 02] Available from: http://www.scielo.br/scielo.php?script=sci_arttext\&pid=S0004-282X2017000800570\&lng=en

C.A.H.G., C.S.M.E., and S.O.O. are members of SEMINEC. C.A.H.G. and D.D.V. are members of CINEPSIS 


\section{Case Reports in Neurology}

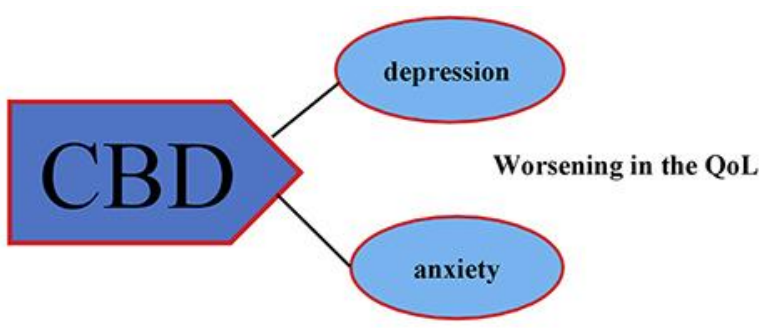

Fig. 1. Influence of depression and anxiety in patients with CBD and how these affect quality of life.

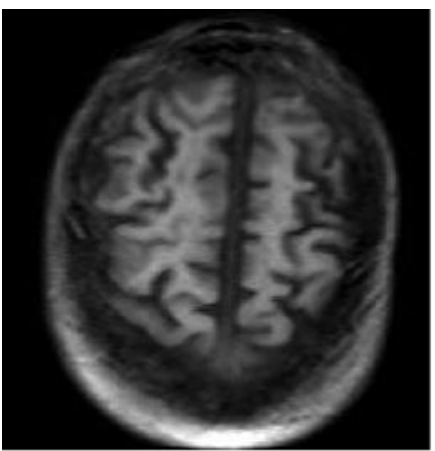

1

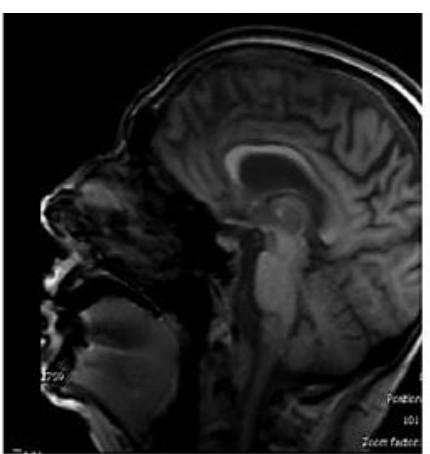

2

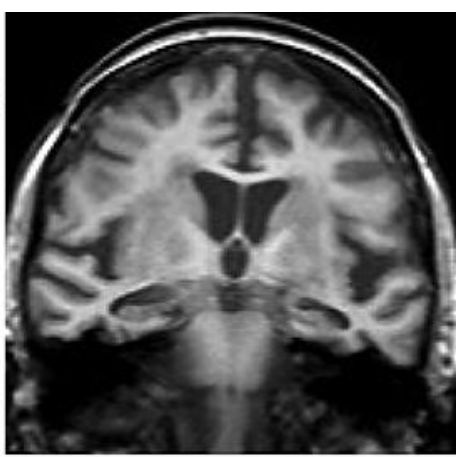

3

Fig. 2. Simple brain MRI of the patient with CBD. 1 Superior vision of the cerebral hemispheres, a decrease in cerebral tissue and/or a volumetric reduction associated with cortical atrophy due to the widening of cerebral grooves is observed, frontal and parietal affectation is identified. $\mathbf{2}$ Middle sagittal section where involutive changes are observed in cerebral grooves associated to severe subcortical atrophy, especially in frontal region, marginal callosal fissure, paracentral lobe and parieto-occipital fissure. 3 Coronal section at the level of the hippocampus. Greater affectation is identified at a temporal level, clinically correlated with grade III hippocampal atrophy. Severe subcortical cortical atrophy continues. 


\section{Case Reports in Neurology}

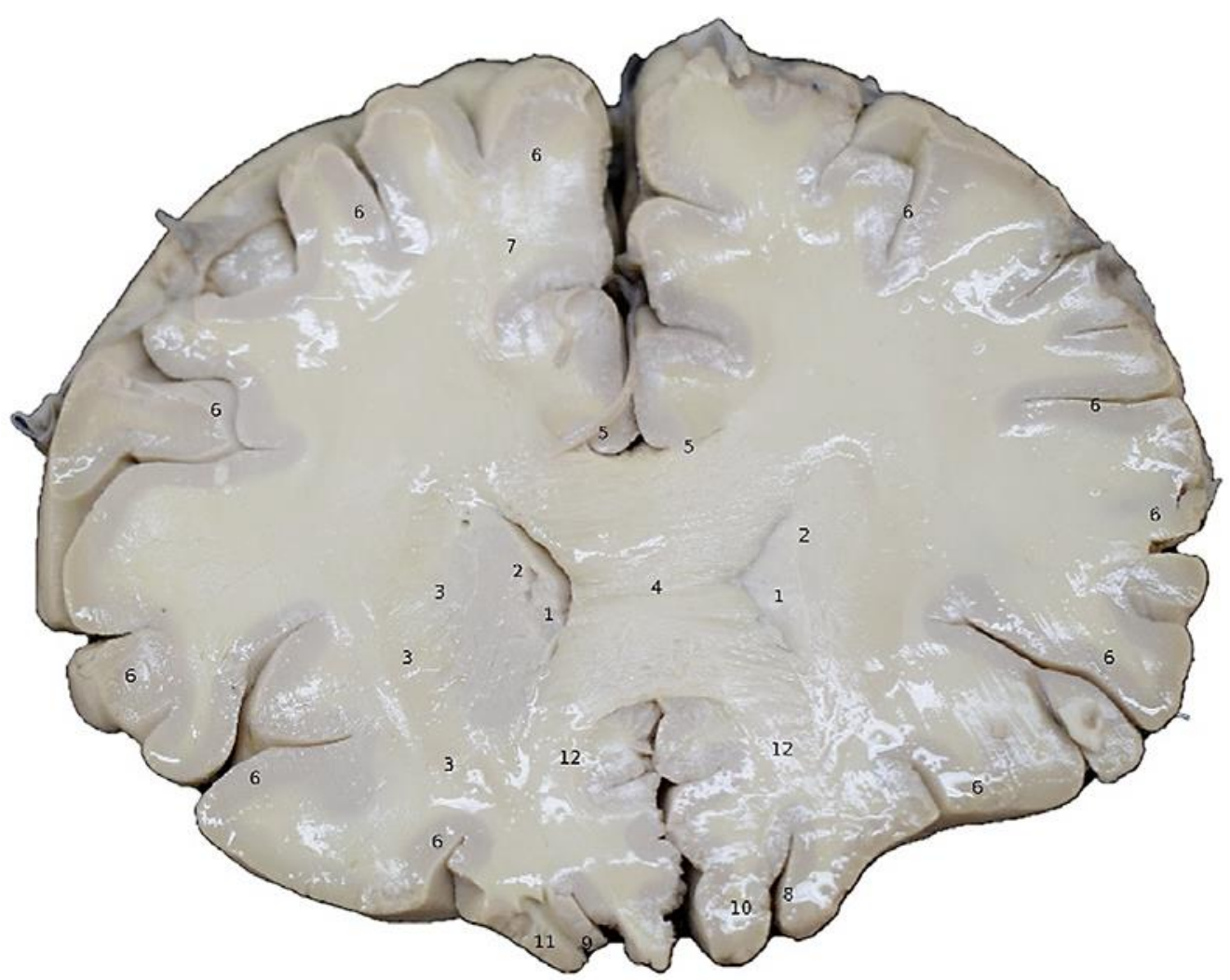

Fig. 3. Prefrontal coronal section at the level of the corpus callosum. The following are identified: (1) frontal extension of the cerebral ventricle; (2) head of the caudate nucleus; (3) internal capsule; (4) corpus callosum body; (5) gyrus cinguli; (6) cerebral cortex; (7) radiated crown; (8) olfactory sulcus; (9) olfactory snood; (10) CBD directly affects the dorsolateral and ventromedial cortex of the brain, generating in the patient a dysexecutive syndrome that is related to a deficit in his behavior and/or immediate behavior. Taken from Corina Brain Research. Digital Application. Faculty of Medicine. Universidad LibreCali (2019). 
Case Reports in Neurology
(C) 2020 The Author(s). Published by S. Karger AG, Basel www.karger.com/crn

Hurtado González et al.: Corticobasal Degeneration in Colombia: A Case Report

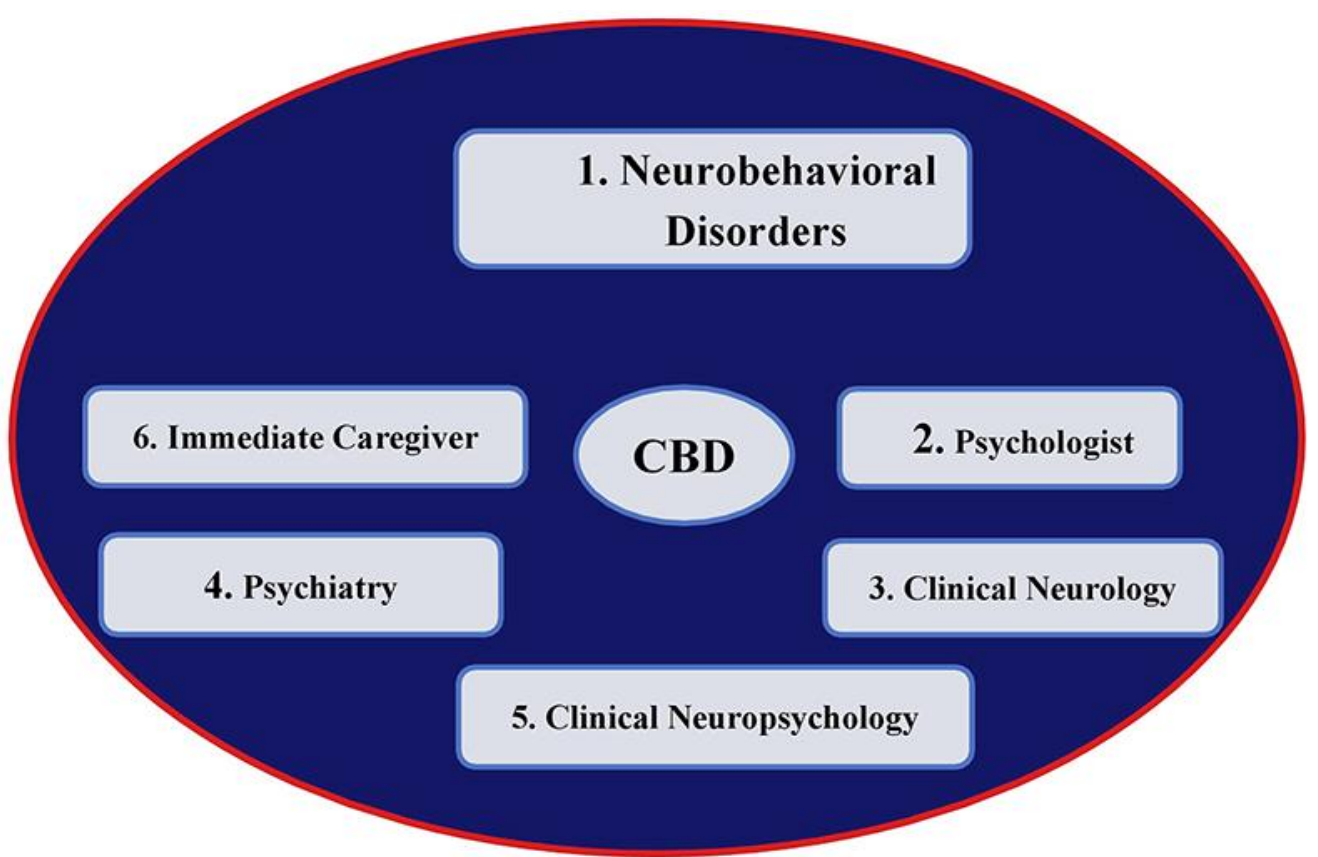

Fig. 4. Proposal for functional neurorehabilitation treatment to improve QOL in people with CBD. 


\section{Case Reports in Neurology}

\begin{tabular}{l|l}
\hline Case Rep Neurol 2020;12:387-401 \\
\hline DOI: 10.1159/000509073 & $\begin{array}{l}\text { (c) 2020 The Author(s). Published by S. Karger AG, Basel } \\
\text { www.karger.com/crn }\end{array}$ \\
\hline
\end{tabular}

Hurtado González et al.: Corticobasal Degeneration in Colombia: A Case Report

Table 1. Results of the neuropsychological evaluation

\begin{tabular}{|c|c|c|}
\hline Materials & Type of test & Results \\
\hline Geriatric Depression Scale & Yesavage depression scale & $25 / 30$ \\
\hline Beck Anxiety Inventory & Anxiety Scale & $40 / 64$ \\
\hline Mini-Mental State Examination (MMSE) & MMSE & $26 / 30$ \\
\hline \multirow[t]{2}{*}{ Digit retention } & Retention of digits & \\
\hline & Direct order & $4 / 16$ \\
\hline \multirow[t]{2}{*}{ Trail making test form $\mathrm{A}$} & Reverse order & $3 / 14$ \\
\hline & TMT Form A & she could not do it \\
\hline Trail Making Test Form B & TMT Form B & she could not do it \\
\hline \multirow[t]{2}{*}{ Babcock's Story Immediate and Deferred Memory } & Immediate Babcock Story & $4 / 21$ \\
\hline & Babcock Story Deferred & $2 / 21$ \\
\hline \multirow[t]{2}{*}{ Clock test } & Clock test order & $2 / 10$ \\
\hline & Clock test copy & $1 / 10$ \\
\hline \multirow[t]{2}{*}{ Verbal fluency } & Animals & 2 \\
\hline & Persons & 4 \\
\hline Brief Frontal Assessment battery (FAB) & FAB & $10 / 18$ \\
\hline Montreal cognitive assessment (MOCA) & MOCA & $14 / 30$ \\
\hline Barthel's Index & Barthel's Index & $30 / 100$ \\
\hline Lawton and Brody Scale & Lawton and Brody Scale & $3 / 8$ \\
\hline General Health Questionnaire & General Health Questionnaire GHQ-28 & $84 / 84$ \\
\hline
\end{tabular}

